\title{
Microarrayed 2D-SPR Immunosensor for Interleukin-2
}

\author{
Masayasu Suzuki, Yoshinori Kawauchi, Yasunori Iribe \\ Faculty of Engineering, University of Toyama, 3190 Gofuku, Toyama, Toyama 939-8555, Japan \\ suzukimy@eng.u-toyama.ac.jp
}

\begin{abstract}
:
This paper reports high sensitive detection of mouse interleukin-2 (IL-2) in $0.010 \mathrm{~mm}$ i.d. wells, single cell based microwell array, by using a high resolution two dimensional surface plasmon resonance (2D-SPR) sensor and enzyme catalyzed biochemical amplification of SPR signal. In order to detect cytokines from a single cell, sensitivity of $<\mathrm{ng} / \mathrm{ml}$ should be required even if we consider the small volume of microwells $(\sim 1 \mathrm{pl})$. In this study, alkaline phosphatase (ALP) catalyzed precipitation reaction was employed and $0.2 \mathrm{ng} / \mathrm{ml} \mathrm{IL-2}$ could be successfully detected both in buffer solution and culture medium.
\end{abstract}

Key words: surface plasmon resonance, SPR imaging, immunosensor, interleukin-2, microwell array

\section{Introduction}

Detection of cytokines like IL-2 from single cell might contributes basic study on cell-cell communication and development of new medicines. In order to detect cytokines from a single cell, sensitivity of $<\mathrm{ng} / \mathrm{ml}$ should be required even if we consider the small volume of microwells $(\sim 1 \mathrm{pl})$. We have been studying SPR measurement in micro wells whose diameter is $10 \mu \mathrm{m}$, suitable size for single lymphocyte occupation. But the 2D-SPR sensor has lower sensitivity compared with conventional 1D-SPR sensors, and especially in $10 \mu \mathrm{m} \phi$ wells, sensitivity of SPR sensors showed a significant decrease. We have reported sensitivity improvement of 2D-SPR sensor by the use of peroxidase-catalyzed precipitation reaction[1] and $2 \mathrm{ng} / \mathrm{ml}$ of IL-2 could be detected in $10 \mu \mathrm{m} \phi$ wells [2]. In this study, for further improvement of sensitivity, ALP catalyzed precipitation reaction [3] was employed and $0.2 \mathrm{ng} / \mathrm{ml} \mathrm{IL}-2$ could be successfully detected.

\section{Experimental}

The high resolution 2D-SPR imager (2D-SPR 04, NTT Advanced Technologies Corp., Tokyo, Japan) based on Kretschmann configuration was used in this study. Fig. 1 shows the structure of our SPR imager. A collimated beam, generated by a LED source (670 or $770 \mathrm{~nm}$ ) illuminates the gold sensor surface through a coupling prism. The incident beam is TM polarized and the reflected light is imaged onto the cooled CCD camera via a microscopic $7 \mathrm{X}$ lens. High refractive material, SF6 was used for prism and substrate for sensor chip in order to decrease the deformation of SPR images.

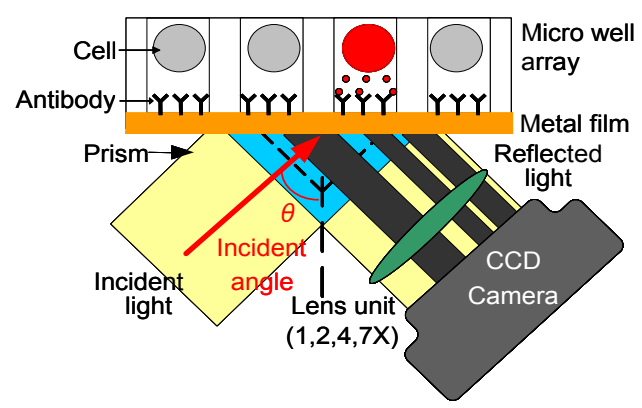

Fig. 1. Structure of 2D-SPR sensor

Micro well array (well diameter: 10um) was prepared by putting the PDMS hole array sheet onto gold sensor film. Anti-mouse IL-2 was immobilized onto gold sensor film via dithiobis (succinimidyl propionate). Measurement is based on sandwich method as shown in Fig. 2. After the sample application, ALP-labelled avidin and biotin labelled anti-mouse IL-2 were added. By the addition of 5-bromo-4-chloro-3indolyl phosphate (BCIP) and nitro blue tetrazolium (NBT), water insoluble NBTformazan were produced and precipitated. This precipitates may cause large SPR signal change. BCIP-NBT solution kit for alkaline phosphatase stain (\#03937-60, Nacalai Tesque, Kyoto, Japan) was used in this study. 




Fig. 2. Principle of biochemical amplification based on ALP-catalyzed precipitation reaction.

\section{Results and Discussion}

As a preliminary experiment, $10 \mathrm{ng} / \mathrm{ml}$ mouse IgG in $30 \mu \mathrm{m}$ microwells was determined by using the ALP-catalyzed precipitation reaction and 2D-SPR sensor. By the use of dithiobis (succinimidyl propionate) (DSP) as selfassembled monolayer (SAM) molecules for antibody immobilization, PDMS microwell array sheet could be surely fixed onto the sensor chip. Fig. 3 shows SPR images obtained before and after mouse IgG addition. Increase of reflected

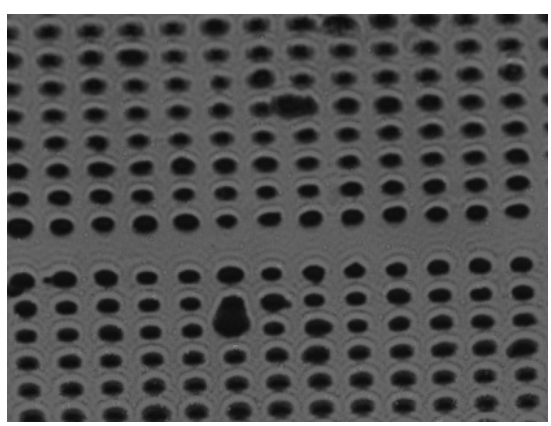

(a) Before $\lg G$ addition

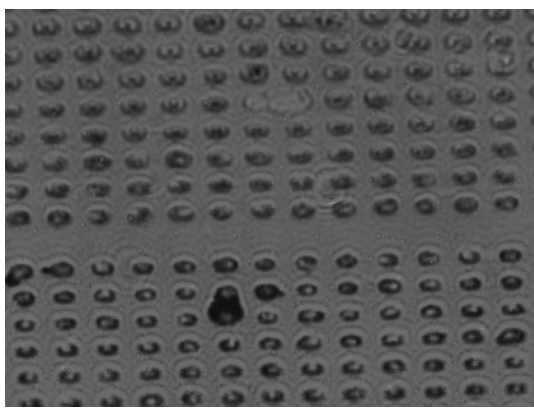

(b) After IgG addition

Fig.3 SPR images obtained before and after mouse Ig $G$ addition light intensity for microwell images caused by the shift of SPR angle could be clearly observed. Then, optimal concentrations of ALPlabelled avidin and biotin-labelled antibody were investigated on the measurement of $10 \mathrm{ng} / \mathrm{ml}$ mouse $\lg G$ in $30 \mu \mathrm{m}$ microwells. Optimal concentrations of ALP-labelled avidin and biotin-labelled anti mouse IgG were $5 \mu \mathrm{g} / \mathrm{ml}$ and $5 \mu \mathrm{g} / \mathrm{ml}$. In case of IL-2 measurement, the same concentrations of ALP-labelled avidin and biotin-labelled anti mouse IL-2 were employed. Mouse IL-2 in $30 \mu \mathrm{m}$ wells was detected under these conditions, as shown in Fig.4. Detection limit of IL-2 was $0.5 \mathrm{ng} / \mathrm{ml}$.

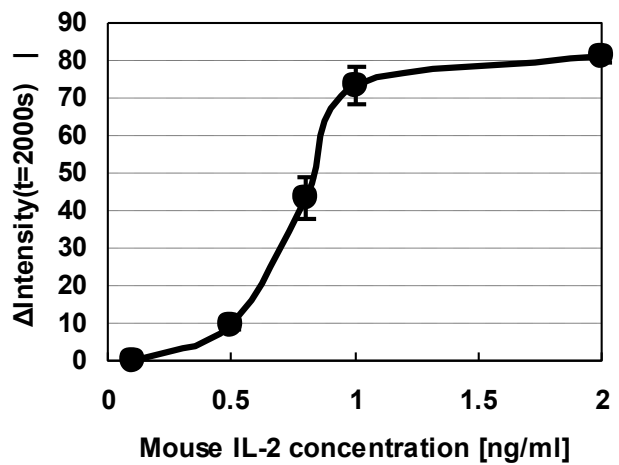

Fig.4 Calibration curve for IL-2 in 30 um microwells $(n=12)$

Final target of the present study is a single cell based immunosensing. Therefore microwell diameter was changed from $30 \mu \mathrm{m}$ to $10 \mu \mathrm{m}$. But sensitivity of SPR sensor was decreased in $10 \mu \mathrm{m}$ wells, as shown in Fig.5 (see $\circ$ and •) By using a shorter wavelength light source (670nm), sensitivity was improved as shown in Fig5 (see $\boldsymbol{\Delta}$ and $\bullet$ ). Therefore 670nm light source was employed hereafter.

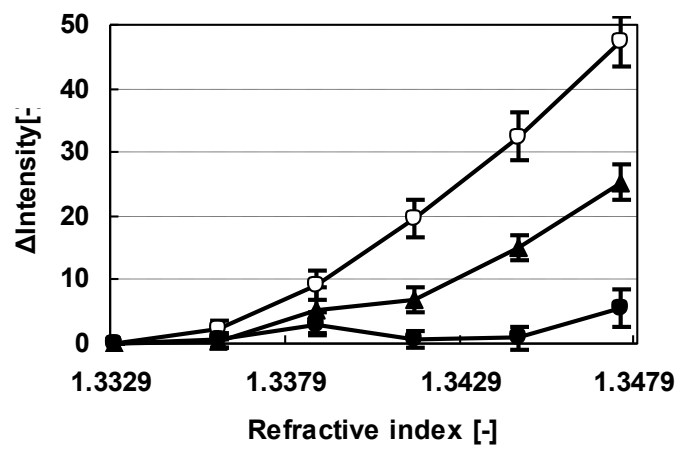

Fig.5 Effects of well diameter and light source on SPR sensitivity $(n=12)$

$\circ 30 \mu m, 760 \mathrm{~nm}, \bullet 10 \mu \mathrm{m}, 760 \mathrm{~nm}, \mathbf{\Delta} 10 \mu \mathrm{m}, 670 \mathrm{~nm}$ 
Under the optimized conditions, IL-2 in $10 \mu \mathrm{m}$ microwells were detected. Fig.6 shows response curves of the $\mathrm{IL}-2$ sensor and the calibration curve for IL-2 was shown in Fig.7. Detection limit of IL-2 was $0.2 \mathrm{ng} / \mathrm{ml}$ and the sensitivity was improved approximately 10 times compared with HRP-catalyzed system [2].

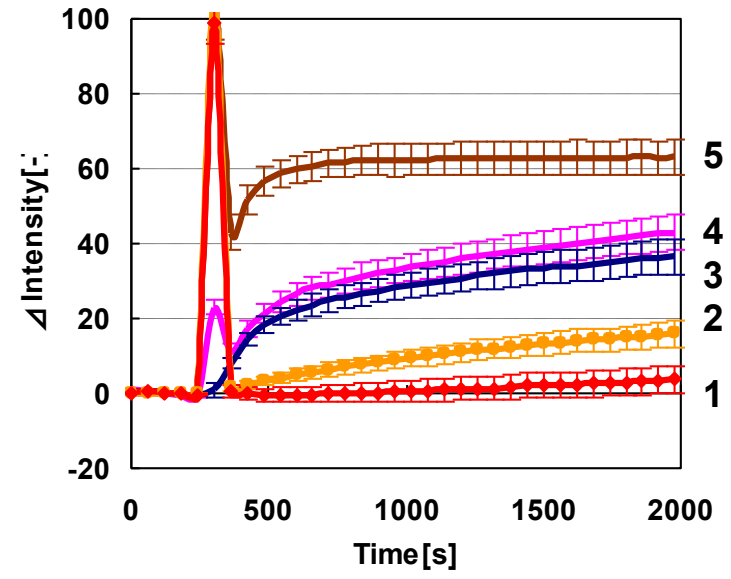

Fig.6 Response curves of IL-2 sensor ( $n=12)$ IL-2 conc. 1: $0 \mathrm{ng} / \mathrm{ml}, 2: 0.2 \mathrm{ng} / \mathrm{ml}, 3: 0.8 \mathrm{ng} / \mathrm{ml}$, 4: $1 \mathrm{ng} / \mathrm{ml}, 5: 5 \mathrm{ng} / \mathrm{ml}$

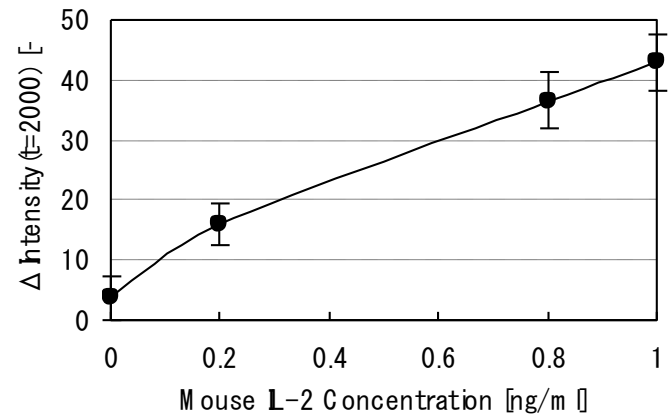

Fig.7 Calibration curve for IL-2 in $10 \mu \mathrm{m}$ microwells

$$
(n=12)
$$

Then IL-2 in culture medium for animal cells was detected by using this sensor system. IL-2 in DMEM medium containing $10 \%$ fetal calf serum was used as samples. As shown in
Fig.8, $0.3 \mathrm{ng} / \mathrm{ml}$ IL-2 could be successfully detected by using this system. This detection limit promises IL-2 detection produced by a single lymphocyte in $10 \mu \mathrm{m}$ micro wells.

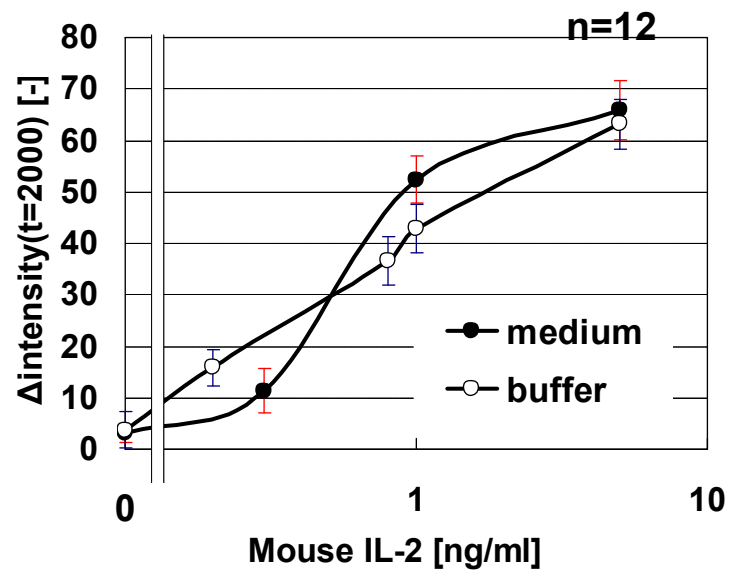

Fig. 8 Calibration curves for IL-2 in 0.05M Hepes buffer solution ( $p H 7.5)$ and DMEM culture medium containing $10 \%$ fetal calf serum

\section{Acknowledgements}

This study was partially supported by research funds for scientific research in priority areas "Life surveyor" from MEXT, Japan.

\section{References}

[1] M.-G.Kim, Y.-B.Shin, J.-M.Jung, H.-S.Ro, B.H.Chung, Enhanced Sensitivity of SPR Immunoassays Using a Peroxidase-Catalyzed Precipitation Reaction and Its Application to a Protein Microarray, J.Immunol. Method 297, 125132 (2005);doi:10.1016/j.jim.2004.12.007

[2] M.Suzuki, S.Hane, Y.Iribe, 2D-SPR Detection of Interleukin-2 in Single Cell Based Microwell Array, Micro Total Analysis Systems 2008 2, 1621-1623 (2008)

[3] H.Tang, Q.Wang, Q.Xie, Y.Zhang, L.Tan, S.Yao, Enzymatically Biocatalytic Precipitates Amplified Antibody-Antigen Interaction for Super Low Level Immunoassay, Biosens.Bioelectron. 23, 668-674 (2007); doi:10.1016/j.bios.2007.08.001 